\title{
Key role players in health care quality: who are they and what do they think? An experience from Saudi Arabia
}

\author{
M.S. Mahrous
}

$$
\text { الأطر اف الرئيسية المؤثرة في جودة الرعاية الصحية: من هم و كيف يفكِّرون؟ خبرات من المملكة العربية السعودية }
$$

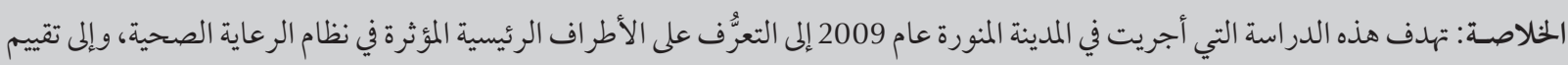

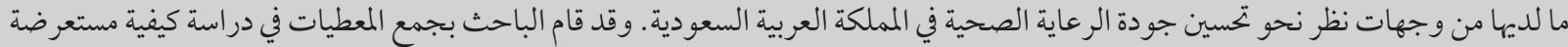

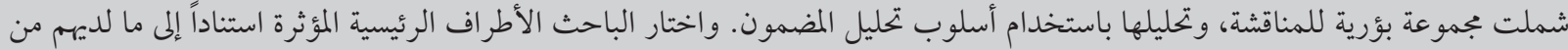

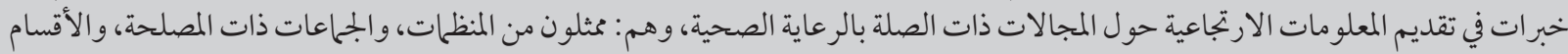

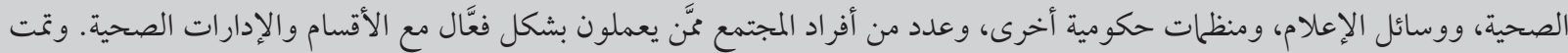

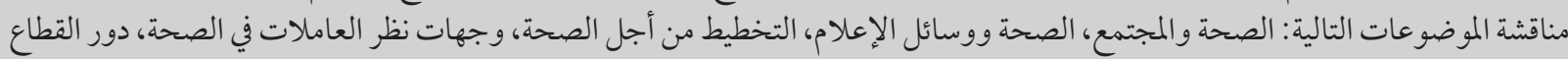

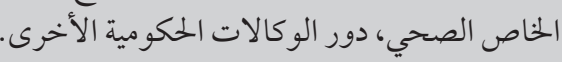

ABSTRACT The aim of this study in Medina city in 2009 was to identify key role players who influence the healthcare system and to assess their views regarding the improvement of the quality of health care in Saudi Arabia. In a qualitative, cross-sectional study data were collected from focus group discussions and analysed using a content analysis approach. Key role players were chosen based on their previous experience in providing feedback in health care-related areas: representatives from organizations, interest groups, departments, the media, other governmental organizations and members of the public who actively worked with the Department of Health. The topics discussed were: health and community; health and media; planning for health; female staff views; role of the private health sector; and the role of other governmental agencies. The discussions highlighted the importance of improvement of health facility infrastructure, the implementation of staff training and education, the initiation of quality assurance and safety standards and the extension of the scope of primary care and community health educational programmes.

Acteurs clés dans la qualité des soins de santé : qui sont-ils et quelle est leur opinion ? Une expérience en Arabie saoudite

RÉSUMÉ La présente étude menée dans la ville de Médine en 2009 visait à identifier les acteurs clés influant sur le système de soins de santé et à évaluer leurs opinions concernant l'amélioration de la qualité des soins de santé en Arabie saoudite. Dans une étude qualitative transversale, des données ont été recueillies à partir de discussions par groupes thématiques à l'aide d'une approche analytique du contenu. Des acteurs clés ont été sélectionnés en fonction de leur expérience en matière de retour d'information dans des domaines liés aux soins de santé : des représentants d'organisations, des groupes d'intérêts, des services, des médias, d'autres agences gouvernementales et des membres du public qui ont activement travaillé au Département de la santé. Les sujets abordés étaient les suivants : la santé et la communauté ; la santé et les médias ; la planification de la santé ; les opinions du personnel féminin ; le rôle du secteur des soins de santé privé ; et le rôle d'autres agences gouvernementales. Les discussions ont mis en évidence l'importance de l'amélioration des infrastructures des établissements de santé, de la mise en oeuvre de la formation et de l'éducation des personnels, de la mise en route de l'assurance qualité et des normes de sécurité et de l'élargissement du champ des programmes de soins primaires et d'éducation sanitaire communautaire.

${ }^{7}$ Department of Medical Education, College of Dentistry, Taibah University, Medina, Saudi Arabia (Correspondence to M.S. Mahrous: mm67sa@yahoo.com).

Received: 18/04/12; accepted: 11/07/12 


\section{Introduction}

Those working in health care today face the challenge, more than ever before, of efficiently utilizing data to improve services and the delivery of care [1]. A key tool is one that provides health planners with feedback about the quality of health services provided and with suggestions about how to implement further improvements that satisfy the needs of the community. Progress towards improvement in the quality of health care is a complex process in which numerous key players have unique roles. Managers, health professionals, patients and other members of the community are all considered to be integral parts of reforming and improving health-care quality. The opportunity to participate in decisions regarding how to improve the quality of health care must be given to all those who have the knowledge and skills to contribute $[2-4]$. South $[5]$ and others $[6,7]$ have set out the advantages of involving key role players in planning and assessment of health care. The importance of incorporating the views of the public as a central element in the development of health systems has been emphasized [7] and studies show that increased public involvement leads to increased responsiveness of the health-care system to the needs of its users and thus to provision of higher quality services $[5,6]$.

Health-care providers and planners in developing countries face huge challenges as a result of the increased cost of health services and the need for a clear vision in the planning of quality health-care services. In Saudi Arabia the Ministry of Health supervises health care and hospitals in both the public and private sectors. The system offers universal health-care coverage in a system characterized by a network of 2037 primary health-care centres and clinics that provide preventive and curative services, as well as mobile clinics for remote rural areas, and at the secondary level by 244 hospitals and specialized treatment facilities located with 33000 beds in urban areas [8]. The Ministry of Health operates $62 \%$ of the hospitals and $53 \%$ of the clinics and centres; the remaining facilities are operated by government agencies, including the Ministry of Defence medical service department, the National Guard Health Affairs, the Ministry of Interior and several other ministries, as well as by private entities.

Finding effective ways to identify and involve key role players from the community in health planning and improvement is a long-standing challenge in Saudi Arabia. The aim of this study in Medina city was to identify key role players who influence the health-care system and to assess their views regarding the improvement of the quality of health care in Saudi Arabia. Medina is one of the 2 holy sites of Islam, visited by large number of visitors throughout the year, especially during times of the Hajj and Umra pilgrimage seasons. This has the potential to overload the health-care system and jeopardize the high-quality services supposed to be delivered to both residents and visitors [9].

\section{Methods}

This was a qualitative, cross-sectional study in which data collected from a survey carried out in Medina city in Saudi Arabia in 2009 were analysed using a content analysis approach [10]. This study lays the foundation for the selection and identification of key role players. The methods used in this study can be divided into 2 parts: first was the identification of key players who were considered to be effectively participating in the process of assessment and feedback; the second was the engagement of these key players in the assessment of the quality of health services.

\section{Selection and nomination of key role players}

Key role players were chosen based on their previous experience in providing feedback in health care-related areas, either as a patient or guardian using health facilities or as a member of another specialized interest group. Representatives from organizations, interest groups, departments, media and local newspapers, other governmental organizations and members of the public who actively worked with the Department of Health were recruited to provide feedback and participate in the assessment of health services.

\section{Obtaining key role players' views on health-care services}

Key role players were grouped into 6 focus groups that consisted of 9 to 13 members each and included a representative from the Department of Health to facilitate the discussion and to document the views of the group. Each group was formed to include people from the same area of interest and/or expertise to ensure the generation of useful information that could guide health leaders in planning services in that area.

Focus group discussions (FGD) were used to generate ideas and feedback for improving the quality of health services and minimizing the gap between what was being provided and the public's needs and expectations. Each group was to discuss one main topic related to the areas of speciality or interest of its members. The following topics were discussed: health and community; health and media; planning for health; female staff views; role of the private health sector; and the role of other governmental agencies. After having the approval of all participants, each group was observed and guided using the FGD technique. The discussions were continued until saturation, when the views and thoughts expressed began to be duplicated. Opinions expressed by each group were documented in writing and followed by qualitative analysis for the findings

\section{Ethical considerations}

This study was approved by the local research ethics committee and waiver of consent form was approved. 


\section{Results}

The results of the different FGD can be classified according to the main topic discussed, as follows:

\section{Health and community}

In this FGD, selected representatives from the public (who had been a patient or someone accompanying a patient), including representatives from nongovernmental organizations, discussed issues related to public and community views on how the quality of services could be improved. The results of this FGD were classified into 2 main parts: what was needed from the Department of Health to assure service quality; and what was needed from the public to allow their continued participation in improving the services provided to them.

\section{Role of the Department of Health}

Regarding the views of the public about what was needed from the Department of Health, 3 main issues emerged. Firstly, the Department of Health should provide quality services through the foundation of modern infrastructure such as hospitals and primary-care centres fully equipped with all necessary equipment and located strategically to match the public health needs of different geographic areas. To operate such health facilities efficiently, the Department should recruit highly qualified and competent staff that can run these facilities in accordance with the new health plan's goals and objectives. A health information system was also highly recommended as a way of reducing the cost of health care and increasing the efficiency of health facilities. Preventive and regular maintenance was also important to the public, as this keeps the infrastructure efficient and ensures that it is prepared to provide the needed services. The public also highlighted the issue of staff education and training with regard to advances in health knowledge and technology. Members of the public stressed the need for health awareness and health education programmes that are directed to them to increase their knowledge and attract their attention to various health subjects.

The second issue brought up by this focus group was the need for primary care services such as disease prevention programmes, as well as the continuity of well-baby care clinics and dental caries prevention programme.

The third issue discussed highlighted the importance of rehabilitation services. The group brought up the need for more efficient rehabilitation programmes.

\section{Role of the public}

The second aspect, related to what is needed from the public to support the role of the Department of Health, was described by the focus group as the need for more connection and direct communication between healthcare facilities and the public in order to maintain healthy relationships that support service development. Financial support and volunteers are urgently needed for effective operation of healthcare facilities. For example, the need for keeping the health-care facilities clean and tidy was noted by the public when they visited the facilities. Finally, public appreciation for the services provided by health-care facilities can play a role in motivating facilities to strive for improvements and this could be done by client satisfaction surveys which can be a routine activity done by the healthcare facilities.

\section{Health and media}

The FGD surrounding this topic yielded innovative ideas about the need for the media to play an important role in partnering with health facilities by providing correct information to the community, especially regarding information about the scope of services provided by health-care facilities. The discussion emphasized the need for the different media sources to have ethically driven missions, visions and values that involve serving as a channel between the community and health facilities. To that end, it was recommended that every media source establish a training programme to enhance the skills of its staff in health journalism and teach the staff how to work with health-care facilities in a way that benefits the health-care system. It was decided that direct contact and clear communication between the media and health-care facilities was the best way to accomplish these aims.

\section{Planning for health}

This FGD can be considered a "control group" because the group was largely composed of health planners and people interested in health planning and assessment, whose views were correlated with the results from other groups' discussions to assure the validity of the methodology of this study. The results here were grouped into $3 \mathrm{sec}-$ tions: health facilities and infrastructure; human resources; and health policy and systems.

\section{Health facilities and infrastructure}

This group's discussion about health facilities and infrastructure and their role in improving service quality resulted in many issues being raised, such as the need for more hospitals and health centres in order to respond to the growing population in a way that assures equity in providing health care to all members of the community, taking into consideration the large number of people present in the holy city of Medina during the Hajj time and Umra seasons.. International standards and guidelines should be consulted when establishing new health facilities to assure that they comply with modern standards and satisfy the needs of the community. Certain expansion projects should be permitted for some of the older, smaller (50-bed) hospitals that were established 60 years ago, to satisfy this need for more and better services. 
Refurbishment and replacement of old equipment with modern equipment was also discussed. The introduction of health information technology was viewed as very important for supporting health planners and professionals in making decisions regarding how to improve health services. Tertiary healthcare centres such as oncology centres were highly recommended to care for cancer patients and reduce the high referral rate of such patients to other centres outside Medina city. Due to the high volume of visitors to Medina city all year long, it was noted that there was a great need for accident and emergency specialized centres positioned along the motorway to Medina.

\section{Human resources management}

The second section of this FGD generated ideas and views from participants about human resources management and how this can play an important role in health care improvement. Issues such as the formation of new jobs and filling vacancies were very important to the overall goal of creating new or extended health facilities. Redistribution of health professionals and staff according to the actual needs of different health facilities, rather than the personal preferences of health professionals, should be undertaken. Providing financial support for continuing education and training programmes would play an important role in improving health services, and create more opportunity for staff to participate in postgraduate or specialized fellowship programmes. The establishment of a system for staff appreciation would reflect on staff performance and loyalty. These ideas could be supported by satisfaction surveys by health-care providers to be part of the health delivery process by all health-care facilities in Saudi Arabia.

\section{Policies and systems}

The third section of the FGD was related to policies and systems and highlighted the lack of guidelines on policy and procedures, including mission, vision and job descriptions that were documented in writing. The group discussed the need for an approved, efficient organizational chart and job description manuals that organize and define every single job and process clearly. The discussion pointed out the need to use the electronic solutions to streamline work processes and eliminate unnecessary pathways, giving health leaders the ability to assess and monitor performance through an electronic system using performance indicators. Full implementation of quality assurance standards, manuals and professional guidelines as well as assessing the need for training courses for the staff on how to implement quality measures in their institutions would facilitate the provision of quality services and the recognition of these facilities by the accreditation organization.

\section{Female staff views}

This FGD was considered unique because it reflected the views of Saudi female health professionals. Recently, an increase in the number of health colleges within Saudi Arabia, including colleges of medicine, dentistry, health applied science and pharmacy, have played a major role in graduating female Saudi health professionals, whereas previously health institutions were operated by non-Saudi female health professionals. The researcher conducting this study very much appreciated the participation of this group in contributing ideas about how to improve the quality of health care.

The discussion of this group focused on the need for more female staff engagement at all levels of health planning and decision-making by giving them a chance for equal participation in all departments and committees, where men have traditionally taken the lead. Moreover, this group emphasized the need for social support systems for female staff, allowing them to balance their work duties and family responsibilities.
The discussions also pointed out the importance of opportunities for women to participate in postgraduate study as well as in continuing training and educational programmes. Raising community awareness about the role of Saudi female health professionals was badly needed for service improvements and for community support for women in these types of positions. The group also stressed the importance of utilizing a health information technology system to improve record keeping and management of patient files, which would reduce costs and improve the efficiency of health services.

\section{Role of the private health sector}

This FGD centred on the partnership style between governmental and private health institutions. It was agreed that to improve the quality of services, public and private sector institutions needed to work together and support each other in a common goal. The discussion also revealed the need to establish a clear policy that recognized the value of expertise within both systems and facilitated the exchange of both ideas and goods, such as medications, vaccinations and other items that were urgently needed but not available within the institution that needs them. There was a need for an effective policy for circulating new regulations, instructions and work policies from the Department of Health to the private health sector. This group also stressed the importance of utilizing a health information technology system on both sides to improve record keeping and management of patient files, which would reduce costs and improve the efficiency of health services provided from both sides. The group brought up the idea of introducing a national health insurance system similar to that implemented in developed countries. This would ensure the availability of affordable, quality health-care services to all clients in Saudi Arabia, alongside the involvement of the private 
health-care facilities in national prevention programmes which might have a great impact on the health for all in Saudi Arabia.

\section{Role of other governmental agencies}

This FGD reflected the views of governmental agencies that work in cooperation with the Department of Health either directly or indirectly, including the Saudi Red Crescent Society, the Department of Justice and the Police Department. The discussion emphasized the role of these agencies as external auditors that monitored and assessed service quality and communicated the views of different service users. The role of these agencies should be highlighted to increase community awareness about the complexity of the health service industry. There was a need for a more efficient e-Government system of communication electronic system of communication that would facilitate efficient sharing of data between the Department of Health and other government departments. Additionally, as previously mentioned in other FGD, the group stressed the importance of utilizing a health information technology system on all sides to improve record keeping and management of patient files. Such a system would reduce costs and improve the efficiency of health services.

\section{Discussion}

The quality of a service can be measured in terms of the level of satisfaction of the recipients of that service. This necessitates the collection of views and feedback from clients who are able to make clear judgments. A review of the literature showed that the results of this study were logical and consistent with the findings reported from other studies and suggested that the methods for selection and classification of key role players used in this study were valid and that the FGD were pertinent to issues related to the improvement of health-care quality.

The FGD highlighted the importance of improvement of health facility infrastructure, the implementation of staff training and education, the initiation of quality assurance and safety standards and the extension of the scope of primary care and community health educational programmes. This was in accordance with the results in England from Campbell et al. [6]. The FGD also emphasized the role of the public in maintaining communication with health facilities and providing feedback to improve the quality of health services; this was also was in accordance to what was found in England by South [11], Campbell [4] and Davis et al. [12]. The FGD emphasized the need to attract and recruit highly qualified health-care professionals who are one of the main pillars of quality health-care services $[5,13,14]$. All groups stressed the importance of utilizing a health information technology system to improve recordkeeping and management of patient files, which would reduce costs and improve the efficiency of health services. This agrees with the study conducted by Zschorlich et al. which revealed that the application of electronic medical records had great impact on the quality and cost of health-care services delivered [7].

Successful selection and nomination of participants will lead to valuable results and feedback that can answer the question concerning defining and nominating key role players: "Who are they?" Results generated from FGD can demonstrate that all ideas put forth are valued and important for improving the quality of health care. The results generated from each of the FGD followed similar patterns of thought and insight as other similar studies $[15,16]$. The similar format of the discussions meant that the same views were frequently expressed by multiple groups. For example, the need for health professionals to be engaged in postgraduate or continuing education programmes was brought up by many groups, and all groups agreed about the need for heath information technology.

It is important to integrate the results of all of these studies and use them as a roadmap for change in the health-care system. In a society such as Saudi Arabia, people may believe that their participation is not important because it is their perception that health planners and professionals already know how best to manage the provision of quality health-care services. It is therefore essential to involve various groups in the decision-making process. If this is not accomplished, the gap between what is being provided and what is really needed will only increase. It is therefore increasingly necessary to identify and recruit key role players to participate in discussions about health care. We believe that the process of selection of these key role players is of utmost importance and that a comfortable atmosphere is crucial for encouraging these key players to participate productively $[4,17-20]$. Additionally, this is not the only method that should be employed in involving key role players in this process: it is believed that the formation of committees composed of key role players coming from different backgrounds would also be an invaluable tool in these endeavours $[5,13,14]$.

\section{Conclusions}

Progress towards improvement in the quality of health care is a complex process in which numerous key players have unique roles. A key tool is one that provides health planners with feedback about the quality of health services provided and with suggestions about how to implement further improvements that satisfy the needs of the community. The FGD approach is 
an applicable and appropriate tool for evaluating and generating suggestions and feedback for the improvement of the quality of health-care services. Many areas in health-care services in Saudi Arabia must be improved to reach an acceptable standard of health care and customer satisfaction. Good selection and classification of key role players is very important for the assessment of health care quality issues and for generating constructive ideas.

\section{Acknowledgements}

The author expresses sincere appreciation to the participants in the focus group discussions.

Competing interests: None declared.

\section{References}

1. Perla RJ, Provost LP, Murray SK. The run chart: a simple analytical tool for learning from variation in health care processes. BMJ Quality and Safety, 2011, 20:46-51.

2. Farrel C. Patient and public involvement in health: the evidence for policy implementation, London, Department of Health, 2004.

3. Gosling L, Edwards M. Toolkits: a practical guide to planning, monitoring, evaluation and impact assessment. London, Save the Children, 2003,

4. Campbell S. Public involvement in community health. Primary Health Care, 2005, 15:42-50.

5. Florin D, Dixon J. Public involvement in health care. British Medical Journal, 2004, 328:159.

6. Campbell SM et al. Changes in patient experiences of primary care during health service reforms in England between 2003 and 2007. Annals of Family Medicine, 2010, 8:499-506.

7. Zschorlich B, Knelangen M, Bastian H. [The development of health information with the involvement of consumers at the German Institute for Quality in Health Care (IQWiG).] Die Entwicklung von Gesundheitsinformationen unter Beteiligung von Burgerinnen und Burgern am Institut fur Qualitat und Wirtschaftlichkeit im Gesundheitswesen (IQWiG). Gesundheitswesen, 2011, 73:423-429.

8. Healthcare and nursing jobs in Saudi Arabia, Qatar and the UAE. Helen Ziegler and Associates [website] (http://www.hziegler. com, accessed 9 July 2013).

9. National project for total and integrated health care. Riyadh, Saudi Arabia, Ministry of Health, 2010.

10. Bowling A. Research methods in health: Investigating health and health services, 2nd. Milton Keynes, England, Open University Press, 2009.
11. South J. Rising to the challenge: a study of patient and public involvement in four primary care trusts. Primary Health Care Research and Development, 2004, 5:125-134.

12. Davies R, Sevdalis N, Vincent C. Patient involvement in patient safety: How willing are patients to participate? BMJ Quality and Safety, 2011, 20:108-114.

13. King $\mathrm{G}$ et al. Exploring public perspectives on e-health: findings from two citizen juries. Health Expectations, 2011, 14(4):351360.

14. Wallcraft J. The person in health care policy development. Journal of Evaluation in Clinical Practice, 2011, 17:347-349.

15. Lowes $L$ et al. Involving lay and professional stakeholders in the development of a research intervention for the DEPICTED study. Health Expectations, 2010, 14(3):250-260.

16. South J. Rising to the challenge: a study of patient and public involvement in four primary care trusts. Primary Health Care Research and Development, 2004, 5:125-134.

17. Gooberman-Hill R, Horwood J, Calnan M. Citizens' juries in planning research priorities: process, engagement and outcome. Health Expectations, 2008, 11:272-281.

18. Krist $\mathrm{AH}$ et al. Patient education on prostate cancer screening and involvement in decision making. Annals of Family Medicine, 2007, 5:112-119.

19. Jones PV, Hughes D, Mullen C. New Labour's PPI reforms: patient and public involvement in health care governance? Modern Law Review, 2009, 72:247-271.

20. Thompson J et al. Health researcher attitudes towards public involvement in health research. Health Expectations, 2009, 12:209-220. 